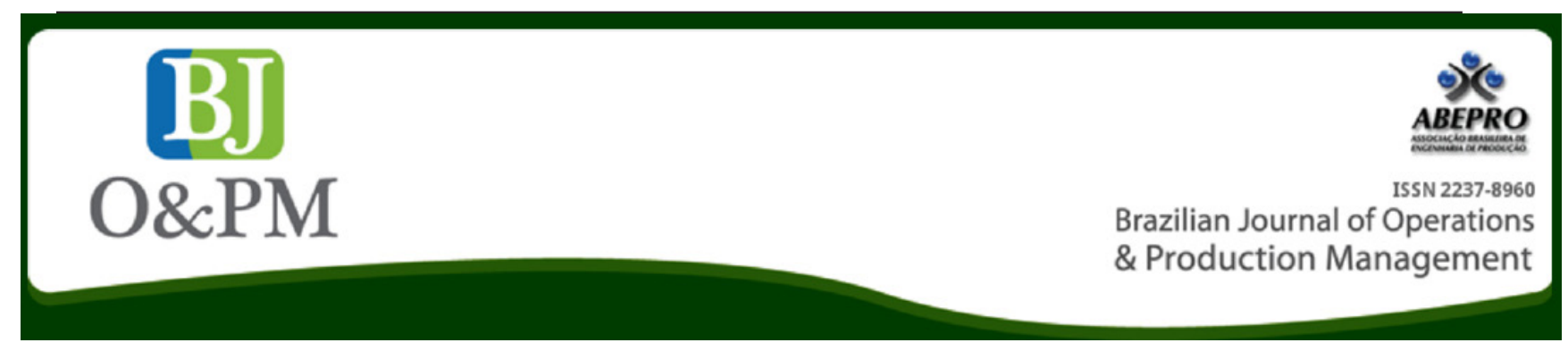

\title{
REVERSE LOGISTICS: THE PORTUGUESE COMPANIES' PERSPECTIVE
}

\author{
Mélodine Fernandes Gonçalves; Ângela Esteves Silva ${ }^{a}$ \\ ${ }^{a}$ Lusíada University - Vila Nova de Famalicão, Portugal
}

\section{ABSTRACT}

The Reverse Logistics has been object of great interest by the whole community. In Portugal, Reverse Logistics is an unfamiliar word in the business world. Due to this fact, it will be interesting to analyze and characterize the Portuguese companies' perspective based on three aspects: The Concept, the Returns and the Environment. For this, semi structured interviews were applied to ten Portuguese companies of different dimensions and industrial sectors. The results showed that all the large companies are aware of Reverse Logistics. The product returns strategies are reuse, sale to the scrap or recycling industries and the environment strategies mostly used by small and medium-size enterprise's (besides waste recycling) are their reuse in the packaging of loads, and by large companies is directed towards recycling, planning routes and the use of recycled materials and reusable packaging. It is understood that, a lot of work in Reverse Logistics is still needed in the context, concerning the companies' awareness to know all their logistics chain (forward and reverse) and in spite of the small and medium-size enterprise's lack of knowledge of the this area, they practice some returns and environmental strategies, but still in a very incipient way.

Keywords: Reverse Logistics; Multicases Study; Concept, Returns and Environment. 


\section{INTRODUCTION}

The Reverse Logistics is an actual and very attractive field of research due to potential of value recovery from the used products, legislations and directives about environmental and consumer laws and social responsibilities (Pokharel et Mutha, 2009). As today's consumers are more and more concerned with the environmental impacts of products and services they buy, enterprises have been more and more concerned with "green operations" because the rapid increase of the industrial activities and uncontrolled consumption of natural resources cause environmental problems (Alfonso-Lizarazo, et al. 2013, Akdoğan et Coşkun, 2012). According to Lopes (200 9), the logistics management activities cannot be limited by only direct flow but also need to consider activities which involves reverse logistics flow. The strong competitiveness, the short life cycle of products, the laws pressure and the ecological awareness are some examples that demonstrate the importance of the development of Reverse Logistics process.

In this way, Reverse Logistics refers to the distribution activities involved in product returns, source reduction/ conservation, recycling, substitution, reuse, disposal, refurbishment, repair and remanufacturing (Akdoğan et Coşkun, 2012). Reverse Logistics potential in recovering the value of used products has been recognized as a source of competitive advantage. However, the process adds costs and Reverse Logistics tends to be more and more investigated and improved by companies. The problems are the lack of studies in the Reverse Logistics area and also the lack of discussion of this topic in the companies. These present circumstances are an obstacle to understanding and implementation of the Reverse Logistics advantages.

Based on it, this study aims to analyze and characterize the Portuguese companies' perspective based on three aspects: The Concept, the Returns and the Environment. This investigation focuses on the companies' knowledge concerning Reverse Logistics, on the Reverse Logistics strategies applied to product returns and on the Reverse Logistics strategies applied behalf the environment.

This paper is organizes as follows. In the next section, detail information concerning systematic literature review and reverse logistics are presented. In section 3 the applied methodology is described, the case-study's methodology using a semi-structured interview in ten companies of different dimensions and industrial sectors. In section 4 describes the results about the Portuguese companies' perspective based on three aspects: The Concept, the Returns and the Environment. The paper ends with the conclusion remarks and outlines future scope of research.

\section{BACKGROUND FOR THE RESEARCH}

In this section, literature reviewed in order to understand all the evolution of Reverse Logistics since 2004 until 2014 are presented, and the results will support the principal goal of this study. The sources of information began by the selection which database will be used to work. All the researches chose database Elsevier Science due to their recognized quality. The idea was to analyze the Reverse Logistic evolution during a specified period. Therefore, the follow term was used for the research: Reverse Logistic, in the title, abstract or keywords of the papers during the period of analysis. Other terms could be used to perform this research but it was decided to focus in the object of this research, to investigate which is related and focused with this specific term. The reference work and books were excluded, in that way only journals were selected. It is considered that all the qualities papers are published in journals.

In the next step, the period $2004-2014$ was selected and a total of 93 papers were obtained. After each article to be analyzed we removed 4 of them (Letter to the editor, Erratum, Corrigendum and Forward) because they did not add any value for the study. So, the database was completed with 89 articles and from each paper the following topics were analyzed: Year of publication; type of journal; origin; the number of authors; the methodology; areas of research and the local of the research (Table 1).

Table 1. Results of relation to analysis of topics.

\begin{tabular}{|l|l|}
\hline \multicolumn{1}{|c|}{$\begin{array}{c}\text { Analysis of } \\
\text { Topics }\end{array}$} & \multicolumn{1}{|c|}{ Results } \\
\hline $\begin{array}{l}\text { Number of the } \\
\text { publications } \\
\text { per journal }\end{array}$ & $\begin{array}{l}\text { The International Journal of Production } \\
\text { Economics was the scientific journal with } \\
\text { more publications. }\end{array}$ \\
\hline $\begin{array}{l}\text { Concept } \\
\text { Evolution in the } \\
\text { period 2004- } \\
\text { 2014 }\end{array}$ & $\begin{array}{l}\text { There was an increase in the number of pa- } \\
\text { pers published in journals, more precisely } \\
\text { since 2010 until 2013. }\end{array}$ \\
\hline $\begin{array}{l}\text { The research } \\
\text { area evolution } \\
\text { over the years }\end{array}$ & $\begin{array}{l}\text { Over the years, the "Supply Chain } \\
\text { Management" topic has attracted more at- } \\
\text { tention than "Environmental". However, } \\
\text { it is noticed an increase in the topic } \\
\text { "Environmental" in the period of 2010 to } \\
\text { 2013 }\end{array}$ \\
\hline $\begin{array}{l}\text { Research meth- } \\
\text { odology }\end{array}$ & $\begin{array}{l}\text { It was observed that the mathematical model } \\
\text { applied in case studies was the methodology } \\
\text { more used, followed by study case. }\end{array}$ \\
\hline $\begin{array}{l}\text { Number of the } \\
\text { authors per } \\
\text { articles }\end{array}$ & $\begin{array}{l}\text { It was observed that 92\% of the articles have } \\
\text { two or more authors and the most of them } \\
\text { have authors from different countries. }\end{array}$ \\
\hline $\begin{array}{l}\text { The origin of } \\
\text { the articles and } \\
\text { the local of re- } \\
\text { search }\end{array}$ & $\begin{array}{l}\text { USA leads with 17 publications and the prin- } \\
\text { cipal local of research is in Universities with } \\
\text { 70\%. }\end{array}$ \\
\hline
\end{tabular}

Source: The authors own 
The research team considered two fundamental areas of research on Reverse Logistic: Supply Chain Management or Environmental issues. Each member classified each paper in one of these areas and all the decisions were taken mutually by the research team. All the articles were examined by the title, abstract, keywords and main body of the paper and none software was used to support these decisions, only Excel was used to organize the data. It is important to emphasize that, not all articles on reverse logistics published during the period of analysis have been published in impact factor journals. There are other prestigious scientific publications, not included in Elsevier Science database, however in future work it should be considered the access to others databases and others terms of research (Gonçalves et Silva, 2014).

Throughout this first stage of the work, the development of research on reverse logistics over the recent years was analysed, by examining the scientific articles appearing in the international journals. The principal goal was to analyse the evolution of the papers on Reverse Logistic published in 2004 until the present time, describe the current situation of the research and provide the support for those who begin the development of this topic.

In accordance with the findings, it can point out the following conclusions: although, there were some earlier works focusing on the Reverse Logistic, this research topic is recent and over the next years everything points to an incredibly interest by the researchers. This increasingly interested in the field, as demonstrated the last four years the progressive growth in the number of the papers (the peak was reached in 2013).

\subsection{Reverse Logistics}

Many researchers in the field of supply chain management have focused on the forward movement (the transformation of the materials from the suppliers to the end consumer, or the forward logistic). Much less attention, however, has been devoted to the field of reverse logistics (Al-Anzi et al., 2007).

Many authors have suggested many definitions for this concept and the proposal of the European Working Group on Reverse Logistics, REVLOG, appears to be the most complete definition. This research group defines Reverse Logistic as "the process of planning, implementing and controlling backward flows of raw materials, in process inventory, packaging and finished goods, from a manufacturing, distribution or use point, to a point of recovery or point of proper disposal always with the purpose of capturing value" (Rubio et al, 2008). Therefore, if the reverse logistics channel is handled well, firms can in fact gain additional benefits from it (Chan, 2011).

Effective reverse logistics focuses on the backward flow of materials from customer to supplier (or alternate disposition) with the goals of maximizing value from the returned item and/or assuring its proper disposal (Autry, 2005). This may include product returns, source reduction, recycling, materials substitution, reuse of materials, waste disposal, refurbishing, repair and remanufacturing (Autry, 2005).

Reverse logistics processes-and reverse logistics researchhas traditionally emphasized green logistics, i.e., the use of environmentally conscious logistics strategies (Autry, 2005). While environmental aspects of reverse logistics are critically important, many firms are also recognizing the economic impact of reverse logistics (Klausner et Hendrickson, 2000).

Effective reverse logistics is believed to result in improved firm outcomes. Firms that effectively manage the reverse flow of goods benefit through decreased resource investment levels and cost reductions, i.e., storage and distribution (Autry, 2005).

The previous literature review gave us the support to understand and analyze the strategies applied in each area: Products returns and Environment.

\subsection{Product Returns}

Once a product enters the reverse logistics flow, the logistics manager has to decide where the product has to be sent: either return to vender, to the landfill, or to the secondary market. There are several reasons why a product enters the reverse logistics flow. Customers return the products for several reasons, for example products once bought may be returned due to physical damage, some of them are returned because the customers are unhappy with the functionality of the product (expectations not met), sometimes customers return products because they discovered an alternative product with better functionality after they have made the purchase and others reasons. There are seven channels for disposing the products that have been returned to the manufacturer: the return to vendor, sell as new, sell via outlet or discount, sell to secondary market, donate to charity, remanufacture/refurbish and materials reclamation/recycling/landfill. Based on the condition of the returned product, contractual obligations with the vendor, and the demand for the product, the manufacturer has one or more of the above options to dispose the returned product (Reddy, 2011).

According to Autry (2005) ,emphasizing a quick and efficient handling of returned product can also be critical in sustaining relationships and creating repeat purchases. For this reason, firms are more willing than ever to accept returns from customers. Reverse logistics allows companies an opportunity to differentiate themselves, builds consumer confidence in the company brand, and positively influences customer satisfaction. As a result, liberal return policies have become a standard marketing practice and a major 
component of the corporate image for many firms in both business-to-business and business-to-consumer markets. The complexity of managing damaged or defective merchandise, product recalls, maintenance and repairs, and recycling should make reverse logistics programs a high priority.

\subsection{Environment}

In recent years, the interest on environment impact has increased for a number of reasons. According to GonzálezTorre et Adenso-Díaz (2006) firstly, as a result of the important negative environmental impacts that company products and processes are producing. Secondly, due to the pressure that society is exerting on its institutions to address environmental issues, which translates as new legal demands (for example, European Union laws require manufacturers to collect and reuse many types of products). Thirdly, managers appreciate the benefits to their company image of adopting environmentally concerned programs. Lastly, consumers have changed their preferences, which are transferred the entire value chain, modifying the responsibilities of suppliers and manufacturers with regards to the products they place on the market. As a result of the aforementioned pressure, environmental practices have been adopted by companies that consist of both increased investment in clean technologies as well as the redesigning of processes and organization.

With the increasing environmental concern, resource reduction, depleting landfill capacities in many countries and enacted obligations by governments to take back the end-of-life products, issues like reverse logistics, product recovery, remanufacturing, and reusing have received growing attention. Implementation of reverse logistics would allow not only for cost savings in inventory carrying, transportation, and waste disposal, but also for the improvement of customer loyalty (Kannan et al., 2012).

Given that an impact on the environment is produced in all the phases of the life cycle of products (elaboration, transport, use or destruction), the integration of environmental questions consequently influences the choice of process technologies, the management of the supply chain or the development of new products. Accordingly, total quality environmental management, life cycle analysis, green supply chain management and ISO 14000 standards are becoming more and more widespread practices (González-Torre et Adenso-Díaz, 2006).

The aim of this environmental strategic viewpoint is to revalue products once they have been thrown away by the end consumer, thus closing/extending their life cycle. Diverse alternatives exist to do so: reutilization, repair, renovation, reprocessing, cannibalization or recycling (González-Torre et Adenso-Díaz, 2006). To put any of these alternatives into practice, companies need to define in collaboration with their customers the changes in their relationship with the goal of returning products at the end of their life span (González-Torre et Adenso-Díaz, 2006).

After this analysis of the different strategies adopted in the product returns and environment, it is important to understand the connection between the literature and the real life and understand if the companies follow some of these strategies.

\section{METHODOLOGY}

In this section, the qualitative methodology used in order to satisfy the principal goal, is presented. The case-study methodology was chosen to gave us a connection between the literature and all the elements that must be taken in field research (Real Oliveira et Ferreira, 2014).

Unlike what happens in quantitative research, in qualitative methodology the research is more focused to find the cause-effect relationship (Soares, 2013). In qualitative methodology, each true is related with a context and a specific time. According to Soares (2013), the importance of the qualitative methodology has been implemented due to the biggest scope of analysis and the number of variables, including phenomena. Taking into account the objective of this study is to adopt the case-study's methodology using a semi-structured interview. The interview is one of the most important sources of information and essential in the case studies (Meirinhos et Osorio, 2010).

According to Meirinhos et Osorio (2010), the interview has one of the most powerful ways to understand the others perspectives and it is a powerful tool to capture the diversity of descriptions and interpretations about what people know on the field. After getting somewhat an idea about Reverse Logistics, a preliminary set of questions were formulated for the case studies. Most of the questions were either taken directly or inspired by the methodology developed by Reddy (2011), for its master thesis work "A study on Reverse Logistics."

"Case study" means a close analysis of the practice, together with the circumstances and its characteristics leading to an understanding of the situation within its own context (Brito, 2004). Subramoniam et al. (2009) proposed an exploratory case study aimed at defining the questions and hypotheses of a subsequent study or defining the feasibility of the detailed research procedure. This methodology was chosen because the case study is used to assess the strategic factors from the literature review and to clarify the questions that require further research.

The case study was applied in different industrial sectors and dimensions (national and multinational) Portuguese enterprises and it was intended to analyze and characterize 
the companies' perspectives, based on three aspects: the concept, the returns and the environment.

This exploratory case study started in the systematic literature review and then, it was delineated all the important questions to get answers from the different industrial sectors companies. The first step was to select the population of this study. It consists of supply chains/logistic managers in thirty Portuguese companies of different industrial sectors and dimensions, located in North of Portugal.

After this selection a formal email was sent to these companies to explain the project and to request their collaboration. The third step was to contact all the companies by phone call and then, we understood the importance to study the perspective about the concept because most of the small companies felt uncomfortable to talk about something they unknown.

This study had the collaboration of ten companies, four of them are Large companies and six are Small and MediumSize Enterprise's (SMEs). Concerning industrial sectors, two companies are the automotive industry; two companies are the cutlery industry; one company is the food industry, one company is the drink industry, three companies are the aluminum industry and one company is the retail industry.

The case study was conducted through semi-structured interviews with open-ended questions. This study was divided in three research areas and each area has a research question which results the interview questions (Table 2 ). This type of interview does not follow any previously established order about the questions designed and allow more flexibility because it is possible to put the questions in the appropriate time according to the interviewee's answers (Meirinhos et Osorio, 2010).
Table 2. Research areas and questions

\begin{tabular}{|c|c|c|}
\hline Research Areas & Research questions & Interview questions \\
\hline $\begin{array}{l}\text { Product } \\
\text { Returns }\end{array}$ & $\begin{array}{l}\text { What are the } \\
\text { Reverse Logistics } \\
\text { strategies used } \\
\text { by Portuguese } \\
\text { Companies on the } \\
\text { product returns? }\end{array}$ & $\begin{array}{l}\text { What are the principal } \\
\text { reasons for returns? } \\
\text { How is the returns pro- } \\
\text { cess (flow) adopted by } \\
\text { your company? } \\
\text { What activity (ies) / } \\
\text { strategy (ies) apply, in } \\
\text { order to get value from } \\
\text { your products returns? }\end{array}$ \\
\hline Environment & $\begin{array}{l}\text { What are the } \\
\text { Reverse Logistics } \\
\text { strategies used by } \\
\text { Portuguese compa- } \\
\text { nies on the environ- } \\
\text { ment? }\end{array}$ & $\begin{array}{l}\text { What are the Reverse } \\
\text { Logistics strategies } \\
\text { directed to the envi- } \\
\text { ronment? Packages } \\
\text { type? Planning routes, } \\
\text { collection points and } \\
\text { time? Correct disposal } \\
\text { of waste? Recycling? } \\
\text { Reuse materials, } \\
\text { products, package? } \\
\text { Materials recovery? }\end{array}$ \\
\hline Concept & $\begin{array}{l}\text { What is the com- } \\
\text { pany's perception } \\
\text { about Reverse } \\
\text { Logistics concept? }\end{array}$ & $\begin{array}{c}\text { Have you heard about } \\
\text { the term reverse logis- } \\
\text { tics? If yes, what do you } \\
\text { understand by it? } \\
\text { In your point of view, } \\
\text { what is the importance } \\
\text { of reverse logistics in } \\
\text { companies? }\end{array}$ \\
\hline
\end{tabular}

Source: The authors own.

The interviews were recorded, on audio format, and always with the agreement of the interviewees. It is very important to respect their space and if they want to remain anonymous or confidentiality of their information. Finally, we used WebQDA software to analyze to qualitative information.

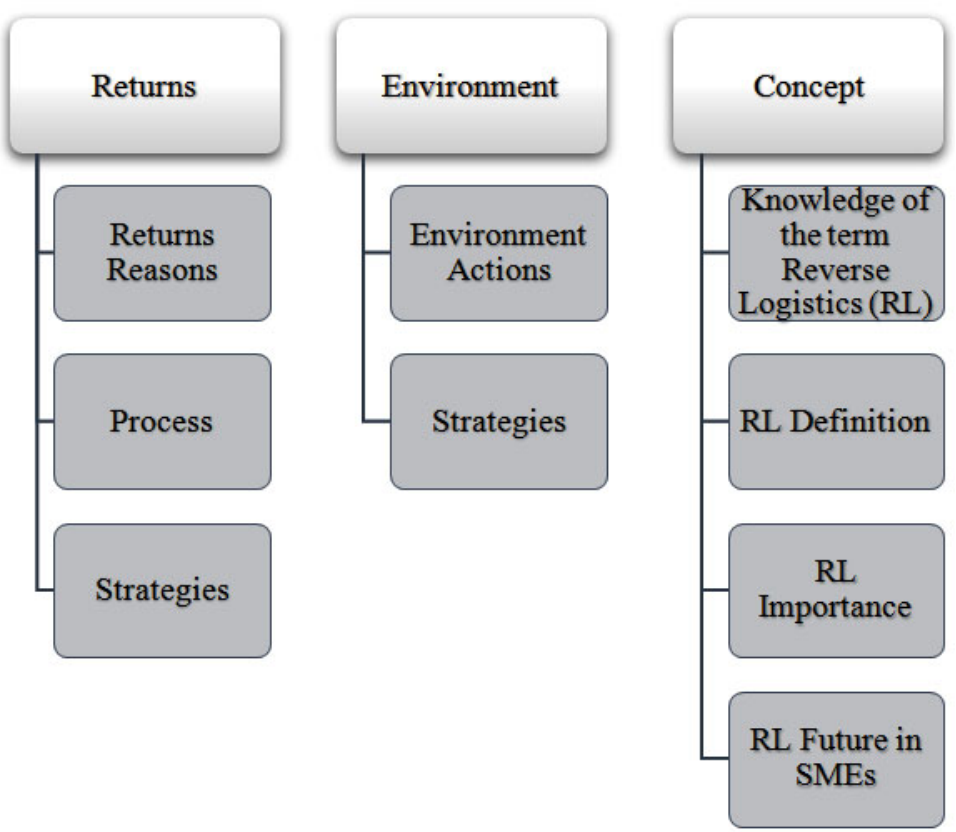

Figure 1. Categories and subcategories created from WebQDA software. Source: The authors own. 


\section{RESULTS}

After applied the semi-structured interview in ten Portuguese Companies the results were obtained by the WebQDA software. For a better understanding of interviews information, three categories were created (Returns, Environment and Concept) and subcategories (Figure1). As it can be seen, each category has specific subcategories that are connected with the respective category.

\subsection{The Products Returns}

The Returns category is subdivided as: the reasons of the returns, the reverse logistic process and the reverse logistics strategies used by Portuguese companies. The results indicates the reasons of the returns mentioned by most productive companies and transportation.The aluminum and automotive companies indicated the same reason (production) and the other companies indicated different reasons, realizing that the reason connected with the type of industrial sector.

All the participants agreed that the customers are more demanding with the products, service and others factors. About the process, when the company has a product return, the communication is done between the customer and the company by email or phone call, and after that some companies collected the returned products and others the customer may turn directly to the company. All the Large companies collected the products returns while in Small and Medium-Size Enterprise's the scenery is different. Concerning the product inspection, nine of the ten companies studied inspect the product returns through quality department.

Concerning the reverse logistics strategies, it was observed that the elimination is the strategy most used by the companies (six SMEs and two Large companies). Companies show that the best way to make value from products returns is to sell them to the scrap or industries that will transform the product in by-products. Moreover, the second strategy applied by seven companies (four SMEs and three Large) is reuse. Although, this strategy can be mentioned as a second option, it was observed that six companies prefer to reuse their products firstly and after, if they cannot be reused they are eliminated. As for the industrial sector, it was observed all the companies reuse the products except food company. Two aluminum companies apply repair; one cutlery company transform their products by polish and the retail company was the only company to apply redistribution and resale products (seasonal products).

\subsection{The Environment}

In the category Environment, the data analysis is focused on two subcategories as follows.The environment actions applied by the companies and the reverse logistics strategies regarding environment.
At this time, it is intended to analyze not only how the companies deal with the law pressures or environmental regulations, as well as the strategies applied in favor to environment and how the products should be correctly eliminated. Based on it, it was asked to the participants if they had the necessity to adopt environment actions in their companies and the answers, regardless the type of industry or size, were positive. Furthermore, it was noticed that when the environment theme was approached all the companies seemed to be very sensitive with environment and they insisted on showing how their certification and to say that they respect all the environmental obligations.

Concerning that the reverse logistics strategies apply to the environment, we observed that all the companies recycle their waste/products (paper, cardboard, plastic, paint, aluminum and others) and the elimination involves sale the waste/products to the scrap, recycling industries or just sent to landfill/incineration. One aluminum company reuse their sludge from the wastewater treatment for Minho University project and the drink company used the gas produced, turning it into fuel for the company. The strategies mostly used by SMEs (besides waste recycling) are their reuse in the packaging of loads. However, the focus of Large companies is directed towards recycling, planning routes and the use of recycled materials and reusable packaging.

\subsection{The Concept}

The concept was focused in four subcategories as follows. The knowledge of the term reverse Logistics, definition, importance and the future of reverse logistics in SMEs. The last three subcategories were analyzed by only the five companies who knows the term.

The results suggested that all the Large companies are aware of Reverse Logistics, except for one of the Small and Medium-Size Enterprise's. Having in mind the definition of reverse logistics by Rogers et Tibben-Lembke, 1998 "The process of planning, implementing, and controlling the efficient, cost-effective flow of raw materials, in-process inventory, finished goods, and related information from the point of consumption to the point of origin for the purpose of recapturing value or proper disposal." We asked the companies which knows the term to define it, and three companies (two large and one SMEs) said the same thing "It is everything since the consumption point to the origin" and the others (Retail and Drinks, two large companies) defined it according to the importance that Reverse Logistics have in their specific company.

Through the answers, we conclude that any company gave a complete definition like literature said, however it should be noted, according to Kivinen (2002) each person has a different perspective of reverse logistics concept because that depends on which area they are inserted. So, 
it is important that each person should indicate how the reverse logistics needs to be understood by all the parts, because it is possible to find different perspective of what reverse logistics is.

Concerning the importance of reverse logistics, all the companies agreed the importance and the benefits of reverse logistics as help the process return, minimize costs and help the environmental issues (use recyclable raw materials, reuse and others). Finally, about the future of reverse logistics in SMEs, two different types of perspective were observed, one perspective by one SMEs and one large company affirms that the reverse logistics is an area that SMEs needs to bet because they become stronger and more competitive, however for three Large companies they believe to be very difficult to implement it because SMEs does not have management tools, investments, systems, logistics platforms to support reverse logistics. So, these three companies said the way could be the outsourcing to help this "little" companies.

\section{CONCLUSIONS AND FUTURE RESEARCH}

In this section we intend to present the conclusions of this paper. This process of investigation allowed the reverse logistics approached into two parts: analyze the evolution of the reverse logistics research between 2004-2014; and to analyze and characterize the Portuguese companies' perspective based on three aspects: The Concept, the Returns and the Environment. All this investigation contributed to the exploration and development of this area in Portugal. Understanding if the theme is or not known, if the companies practice reverse logistics strategies directed to the products returns and the environment, this way it lead us to understand the extent to which the theme is inserted in companies, its importance and what is its future.

It was conducted a semi structured interview applied in ten Portuguese companies of different dimensions (small and medium size enterprises and large companies) and of varied industrial sectors (Aluminum, Automotive, Drinks, Food, Cutlery and Retail), in the North of Portugal.

The analysis of the interviews (with WebQDA software) gave the opportunity to understand that all the big companies are aware of Reverse Logistics, except for one of Small and Medium-Size Enterprise's (SMEs).As for the Reverse Logistics strategies applied to the product returns, this research has showed that the most common strategies are the reuse of the products or their sale to the scrap or recycling industries, although there are some particularities depending on the type of industry. Furthermore, the present work has concluded that all the companies recycle their wastes / products (paper, cardboard, plastic, aluminum, etc) and that their elimination involves either the products or waste sale to recycle or scraps companies or these are sent to a landfill or incineration plant. So, the strategies mostly used by SMEs (besides waste recycling) are their reuse in the packaging of loads. However, the focus of large companies is directed towards recycling, planning routes and the use of recycled materials and reusable packaging.

It is understood that a lot of work in Reverse Logistics is still needed in the context, concerning the companies' awareness to know all their logistics chain (forward and reverse) and in spite of the SMEs lack of knowledge of the area (Reverse Logistics), they practice some returns and environmental strategies, but still in a very incipient way.

In future research, it would be interesting to focus on companies that know Reverse Logistics area and apply a quantitative methodology (surveys) across the country (Portugal) in order to analyze the reasons and the difficulties that they felt on Reverse Logistics implementation.

\section{REFERENCES}

Alfonso-Lizarazo E.H., Montoya-Torres J.R. and GutiérrezFranco, E. (2013), Modeling reverse logistics process in the agro-industrial sector: The case of the palm oil supply chain. Applied Mathematical Modelling, Vol. 37 No. 23, pp. 96529664.

Akdoğan M. and Coşkun A. (2012). Drivers of Reverse Logistics Activities: An Empirical Investigation. Procedia Social and Behavioral Sciences, Vol. 58 No.2012, pp. 16401649.

Al-Anzi, F. S., Allahverdi, A. and Kovalyov, M. Y. (2007), Batching deteriorating items with applications in computer communication and reverse logistics. European Journal of Operational Research, Vol. 182 No.3, pp.1002-1011.

Autry, C.W. (2005), Formalization of reverse logistics programs: A strategy for managing liberalized returns. Industrial Marketing Management, Vol. 34 No.7, pp, 749757.

Brito, M. (2014), Managing Reverse Logistics or Reversing Logistics Management? Thesis of Series Research in Management, University Rotterdam, Holland.

Chan, H. K. (2011), Green process and product design in practice. Procedia - Social and Behavioral Sciences, Vol.25, pp.398- 402

García-Rodríguez, F.J., Castilla-Gutiérrez, C and BustosFlores, C., (2013) Implementation of reverse logistics as a sustainable tool for raw material purchasing in developing countries: The case of Venezuela. International Journal of Production Economics, Vol.141 No.2, pp. 582-592.

Gonçalves, M. and Silva, A. (2014) Analysis of the Research on Reverse Logistic (2004 - 2014). Proceedings International Conference IS2014 - Innovation for Sustanability Is your 
Responsibility, Universidade Lusíada do Porto, Porto, Portugal, 10 e 11 de Julho.

González-Torre, PL, Adenso-Díaz, B (2006), Reverse logistics practices in the glass sector in Spain and Belgium. International Business Review, Vol.15 No.5, pp.527-546.

Kannan, D., Diabat, M., Alrefaei, K. and Yong G. (2012), A carbon footprint based reverse logistics network design model. Resources, Conservation and Recycling, Vol.67 No.10, pp.75-79.

Klausner, M. and Hendrickson, C.T. (2000), Reverselogistics strategy for product take-back. Interfaces, Vol.30 No. 3, pp.156- 165.

Lopes, D. (2009), Uma Contribuição na Estrutura dos Fluxos Logísticos Reversos das Lojas de Departamentos. Universidade Federal do Rio de Janeiro.

Meirinhos, M. and Osório, A. (2010), Educação O estudo de caso como estratégia de investigação em educação. EDUSER: Revista de Educação, Vol. 2 No.2, pp.49-65.

Pokharel S. and Mutha A. (2009), Perspectives in reverse logistics: A review. Resources, Conservation and Recycling, Vol.53 No.4, pp. 175-182.

Reddy, D. (2011), A study on Reverse Logistics. Master Program In Product And Process Development production \& logistics, Malardalen University, Sweden.

Rubio S., Chamorro A. and Miranda J.F. (2008), Characteristics of the research on reverse logistics (19952005). International Journal of Production Research, Vol. 46 No.4, pp. $1099-1120$.

Silva, D., Renó, G., Sevegnani, G., Sevegnani, T. and Truzzi, O. (2013), Comparison of disposable and returnable packaging: a case study of reverse logistics in Brazil. Journal of Cleaner Production, Vol.47 No.3, pp.377-387.

Soares, E. (2013), Tradução, adaptação e validação do conteúdo do instrumento Assessment of Peer Relations tendo em conta a realidade cultural portuguesa. Tese de Doutoramento em Estudos da Criança. Especialidade em Educação Especial. Universidade do Minho, Portugal.

Subramoniam, R., Huisingh, D. and Chinnam, R. (2009), Remanufacturing for the automotive aftermarket-strategic factors: literature review and future research needs. Journal of Cleaner Production, Vol. 17 No.13, pp. 1163-1174. 